\title{
Extracts of plants used as traditional medicines have toxic effect on the liver and kidney
}

\begin{abstract}
Vegetables and fruits are natural sources of useful antioxidants. Plants and their extracts are widely used as traditional medicine. In Southeast Asia region, Syzygium polyanthum, Octomeles sumatrana and Hylocereus polyrhizus are used in treatment of diabetes mellitus. This study was designed to investigate the safe use of extracts of these plants on liver and kidney.
\end{abstract}

Experimental female rats were divided into nine groups. One group was normal non diabetic control given normal saline; four groups were normal non diabetic animals of which three were treated with plant extracts, while one group, the control, was daily orally treated with vitamin E $(250 \mathrm{mg} / \mathrm{kg}$ body weight). The remaining four groups were diabetic animals (one group was control animals treated with normal saline and three groups were treated with plant extracts). The plant extracts were administered for two weeks as daily oral single doses. Doses of Octomeles sumatrana and Syzygium polyanthum were $1 \mathrm{~g} / \mathrm{kg}$ body weight while that of Hylocereus polyrhizus was $3 \mathrm{~g} / \mathrm{kg}$ body weight.

Normal and diabetic rats treated with plant extracts demonstrated toxic changes in their liver and kidney. Liver showed damaged hepatocytes with macrophage infiltration. Kidney displayed interstitial bleeding, arterial and arteriolar wall thickening and glomerulosclerosis.

Findings in this study go with the previously published reports on the damaging effect of exogenous toxins and plants extracts on the liver and kidney. This work demonstrated the importance of safety studies on herbal extracts.

Keywords: Toxicity, Plant extracts, Liver toxicity, Renal toxicity, Syzygium polyanthum, Eugenia polyantha, Octomeles sumatrana, Hylocereus polyrhizus
Volume 5 Issue I - 2018

\author{
Abdul Ameer H Dhiab Al-Nuaimi \\ Department of Anatomy, Al-Balqa Applied University, Jordan
}

Correspondence: Abdulameer Al-Nuaimi, Department of Anatomy, College of Medicine,Al-Balqa Applied University,AlSalt, Jordan, Email abdulameerh@yahoo.com

Received: December 15, 2017 | Published: January 29, 2018

\section{Introduction}

Vegetables and fruits have potential therapeutic effects in the management of many human diseases. ${ }^{1-4}$ Many bioactive compounds have been isolated from plants and fruits; they are a good source of antioxidants which aid the protection against oxidative stress. ${ }^{5,6}$

Plants and their extracts have been used as traditional medicines for the management of a variety of diseases in many Asian countries. Among these plants are Syzygium polyanthum, Octomeles sumatrana and Hylocereus polyrhizus.

Syzygium polyanthum (Myrthaceae) is synonymous with Eugenia polyantha. It is locally known as daunsalam or seraikayu or as Indonesian bay leaf. ${ }^{7}$ Leaves of the plant are used to flavor food. ${ }^{8}$ The leaf extract showed antimicrobial activity and is said to be beneficial in hypercholesterolemia, diabetes mellitus, high blood pressure, stomach disorders and diarrhea. ${ }^{9}$

Octomeles sumatrana (Datiscaceae) is a riverine specie with relatively light, soft wood. It has poor resistance to decomposition, thus is consequently used where strength and durability are of less importance as in the manufacturing of pulp, wood containers and match boxes. O. sumatrana barks are a rich source of bioactive compounds. They are boiled in water and taken orally by the Kadazandusun people of Sabah, Malaysia as a tonic and in the treatment of body aches, muscle spasms and in stressful situations.

Hylocereus polyrhizusis a fruit from the climbing cacti of the Cactaceae family. ${ }^{10}$ The plant originated from Latin America ${ }^{11}$ and is widely cultivated throughout Malaysia. The fruit gains its local name, red dragon fruit, from its purple-red scaled structured skin. The flesh is edible and is of a brilliant purple-red color and is scattered with small edible black seeds. Each ripe fruit can weigh between 200 to $500 \mathrm{~g}$. The fruit exhibits antioxidant properties from its high content of vitamin $\mathrm{C}$ and dietary fibre. ${ }^{12}$

It is known that fruits and plants are excellent sources of antioxidant polyphenols, thus extracts of plant materials which targeted the health industry are available commercially. Plant extracts contain concentrated amounts of phytochemicals can be toxic in high doses as previously noted. ${ }^{13}$ Histologically, some studies showed that, exogenous toxins and high doses of plants extracts was harmful to the liver ${ }^{14,15}$ as well as to the kidney. ${ }^{16}$

Not much work has been done on $S$. polyanthum, O. sumatrana and $H$. polyrhizus despite their widespread use by Malaysians. These plants have been investigated in the Faculty of Pharmacy, UiTM laboratories in the last few years for evidence of their benefits as used in folk medicine. The present study was designed to assess the safe use of these extracts on the liver and kidney of normal and streptozotocininduced diabetic rats. 


\section{Materials and methods}

Female adult Sprague Dawley rats (180-200g) were obtained from the Small Animal Production Unit (Multipro Supply, Malaysia). They were randomized into nine groups consisting of six animals each. One group was normal non diabetic control animals given normal saline, four groups were normal non diabetic animals (three groups were treated with the plant extracts while one group was used as a control in which animals were treated with vitamin E) and four groups were diabetic animals (one group was control diabetic animals treated with normal saline and three groups were diabetic animals treated with plant extracts). All groups were housed at a constant temperature $\left(22 \pm 2^{\circ} \mathrm{C}\right)$ in a light-controlled (12:12-h light: dark cycle) room. Animals had ad libitumaccess to water and standard laboratory food (Gold Coin, Brand Animal Feed, A. Sapphire Sdn. Bhd. Malaysia). In order to make the animals diabetic, they were treated with streptozocin (STZ), minimum 98\% HPLC grade, obtained from Sigma-Aldrich, USA. The drug was given as a single dose of $55 \mathrm{mg} / \mathrm{kg}$ body weight intraperitoneally.

One week following the injection, the animals were checked for diabetes. Blood was collected from the orbital sinus, centrifuged and serum level of glucose was analyzed on a Blood Chemistry analyzer (I Lab 300, Italy). Non diabetic and diabetic groups that had been given plant extracts were treated as follows: Each group was fed a different plant extract. Each extract was administered continuously per os as a daily single dose for two weeks. Control diabetic animals were given normal saline.

Plant extracts were prepared from the leaves of $S$. polyanthum, the bark of $O$. sumatrana and $H$. polyrhizus fruit; they were collected from local fields. $S$. polyanthum leaves and $O$. sumatrana bark were dried for three days in an oven at $50^{\circ} \mathrm{C}$, grounded and boiled in water $(100 \mathrm{~g} / 1000 \mathrm{~mL})$ for $15 \mathrm{~min}$. Extracts were filtered through four layers of gauze, centrifuged at $3000 \mathrm{~g}$ for $15 \mathrm{~min}$ and then lyophilized into powder form. Prior to administration to test animals, the extract was prepared by dissolving the powder in normal saline. H. polyrhizus fruits were peeled and the flesh was blended for $10 \mathrm{mins}$ with chilled acetone: water (80:20) in a ratio of 1 part flesh to 4 parts $80 \%$ acetone. The homogenate was centrifuged at $3000 \mathrm{~g}$ for $10 \mathrm{~min}$ at $4^{\circ} \mathrm{C}$. The supernatant was filtered in vacuo and the acetone evaporated under reduced pressure at $40^{\circ} \mathrm{C}$ followed by lyophilization. The powder was dissolved in normal saline prior to administration to test animals.

The extract doses were as follows:

A. O. sumatrana $: 1 \mathrm{~g} / \mathrm{kg}$ body weight .

B. S. polyanthum: $1 \mathrm{~g} / \mathrm{kg}$ body weight.

C. H. polyrhizus: $3 \mathrm{~g} / \mathrm{kg}$ body weight.

D. Vitamin E ( $\alpha$-tocopherol) was prepared in extra virgin olive oil in a dose of $250 \mathrm{mg} / \mathrm{kg}$ body weight ${ }^{17}$ and was given via oral feeding needle, once a day continuously for 2 weeks.

In all cases, animals were killed at $24 \mathrm{~h}$ following the last dose Animals were anaesthetized, the abdomen was opened and the liver and kidney were taken, cut into small pieces and fixed in Orth's fixative. They were then processed and embedded in paraffin. Tissues were cut into $2-3 \mu$ thick sections. Five sections were randomly chosen from each animal of each group (30 slides per group), sections were mounted on slides and stained with Haematoxylin and Eosin (H\&E).
They were studied by light microscopy. Histological changes found in at least $70 \%$ of the slides ( 21 of 30 slides) in each group were taken as significantly positive results (Chi-square test).

Grading of liver histological alterations was done as previously described $^{18}$ as follows:

i. Mild damage: low to moderate grade of necrosis.

ii. Moderate damage: centrolobular lesion.

iii. Severe damage: extensive to very extensive damage, with destruction of hepatocytes in extensive areas or throughout the liver.

Kidney alterations were described accordingly to mild, moderate and severe damage.

\section{Results}

\section{Liver assessments}

Normal control rats, control diabetic rats and non diabetic rats treated with vitamin $\mathbf{E}$ : These animals showed normal liver. Histological examination revealed that the liver was formed of lobules; in the centre of each was a central vein. Hepatic cells (hepatocytes) were polygonal, contained large blue nuclei (sometimes binucleated) and granular pinkish cytoplasm. They were surrounded with well preserved cell membranes. Bile canaliculi between cell membranes were present. Hepatocytes were arranged in laminae which are plates of cells radiating away from central vein. Hepatocytes surrounded endothelial-lined hepatic sinusoids that contained fixed macrophages (Kupffer cells). Sinusoids drain blood into the central vein. At the periphery of hepatic lobules was the interlobular septum with portal triad, the latter contained bile duct; branches of hepatic artery and hepatic portal vein (Figure 1-5).

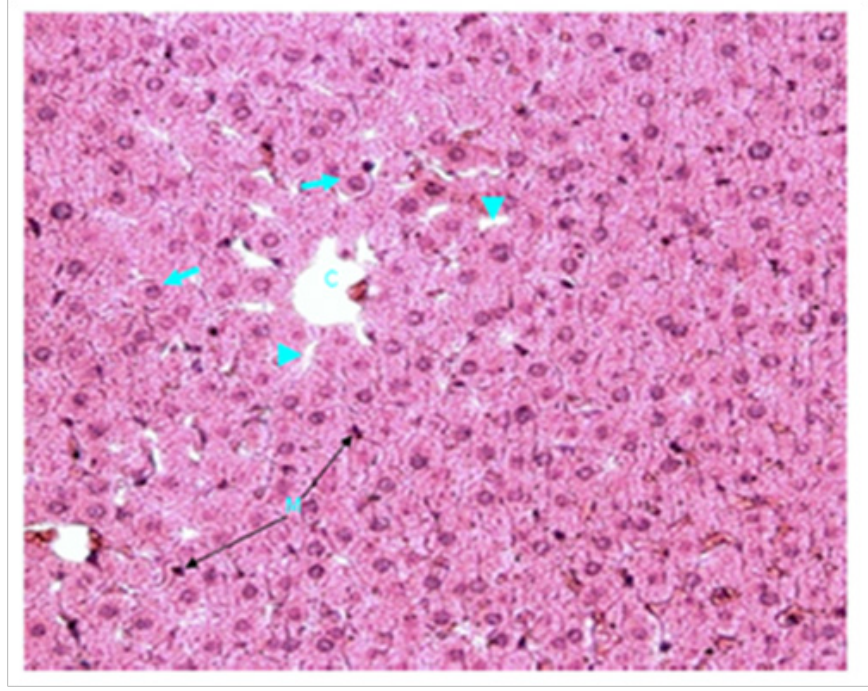

Figure I Light micrograph of a section of normal female adult rat liver stained with H\&E. The central vein $(C)$ is present in the centre of the hepatic lobule. Hepatocytes (arrow) are polygonal, contain bluish nuclei, pinkish cytoplasm and have well preserved cell membranes. They are arranged into plates that radiate away from the central vein toward the periphery of the lobule. Hepatic sinusoids (arrow head) are located between the hepatic plates. Fixed macrophages (Kupffer cells) are present in sinusoid walls (M)X200. 


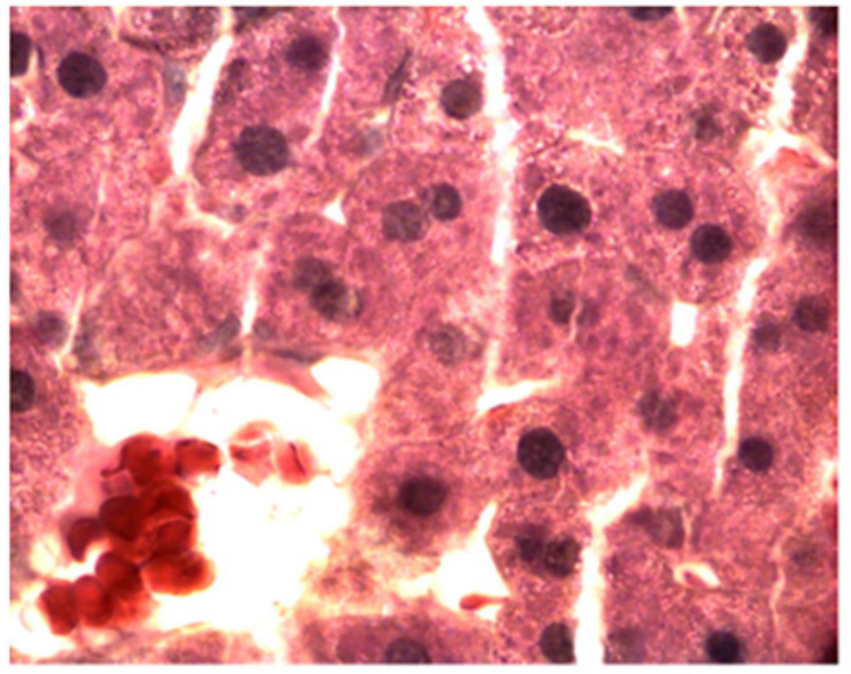

Figure 2 Light micrograph of a section taken from normal adult rat liver stained with H\&E. The central vein $(C)$ is present in the centre of the hepatic lobule. Polygonal hepatocytes (arrow) are arranged in plates that radiate away from the central vein. They contain round bluish nuclei which may occasionally be binucleated (B), they have granular pinkish cytoplasm. Sinusoids (arrow head) are situated between plates of hepatic cells $X 1000$.

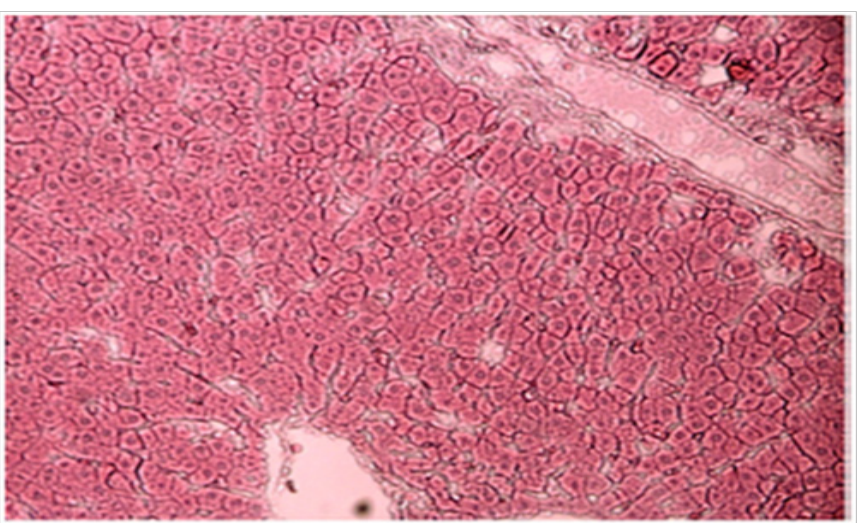

Figure 3 Light micrograph of a section of control diabetic female adult rat liver stained with H\&E. Normal histological features are present. The central vein (C) is in the middle of the hepatic lobule. Hepatocytes (arrow) are polygonal, contain bluish nuclei, pinkish granular cytoplasm and are surrounded by well preserved cell membranes. They are arranged into plates that radiate away from the central vein and surround the hepatic sinusoids (arrow head). Portal triad with branches of hepatic portal vein $(P)$ is seen $X 200$.

$S$. polyanthum treated non diabetic rats: Non diabetic animals given $S$. polyanthum extract showed marked diffuse toxic destruction of the hepatocytes. Damage occurred throughout the hepatic lobules. Most cells were swollen. All forms of damaged nuclei were noticed (small, condensed and fragmented). Some hepatocytes had lost their nuclei. Cytoplasm was granular but sometimes, homogeneous. It is acidophilic and vacuolated. Cell membranes were not clearly visible. Liver tissue was markedly invaded by macrophages. The damage is graded as of severe type (Figure 6).

S. polyanthum extract treated diabetic rats: Animals treated with $S$. polyanthum extract showed marked toxic destruction of the hepatocytes throughout the hepatic lobule. Most of the cells were swollen. Some cells contained small nuclei while others showed condensed and deeply stained nuclei. Some hepatocytes exhibited fragmentation and disappearance of their nuclei. Cytoplasm was granular but in some other cells, it was homogeneous and was pale acidophilic and vacuolated. Cell membranes were not clearly visible. Marked infiltration of the liver with macrophages was noticed. The damage was graded as of severe type (Figure 7) (Figure 8).

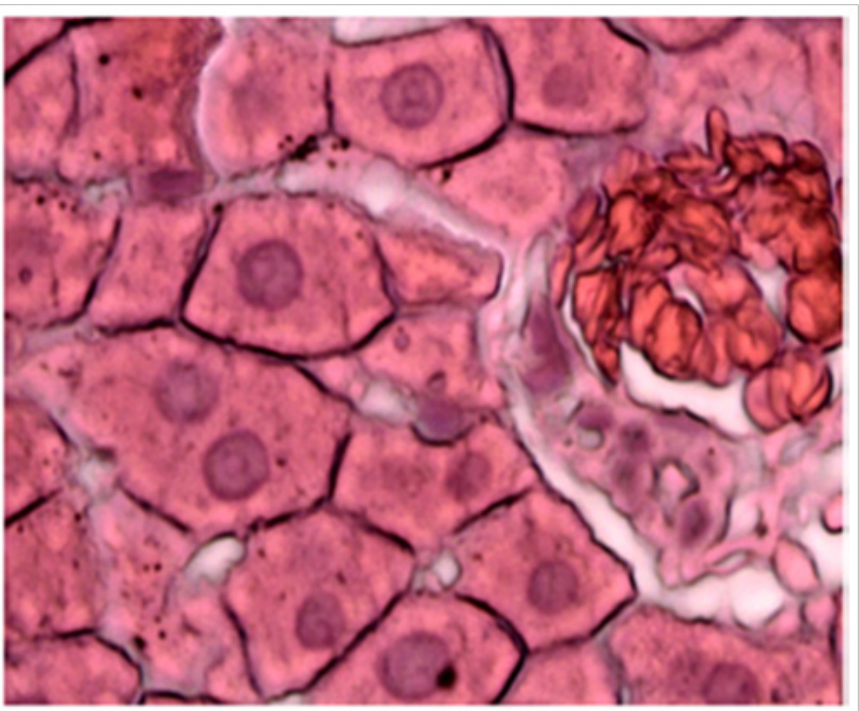

Figure 4 Light micrograph of a section taken from control diabetic rat liver stained with H\&E. Section shows normal histological features. The central vein (C) is located in the centre of the hepatic lobule and contains red blood cells $(R)$, it is lined with endothelial cells (E). Polygonal hepatocytes (arrow) form plates which radiate away from the central vein. Hepatocytes contain bluish nuclei and granular acidophilic cytoplasm, bile canaliculi (BC) is visible between the cell membranes of the hepatocytes. Sinusoids (arrow head) are located between hepatocytes and drain into the central vein. Fixed macrophage (M) to the wall of one of the sinusoids is seen $X 1000$.

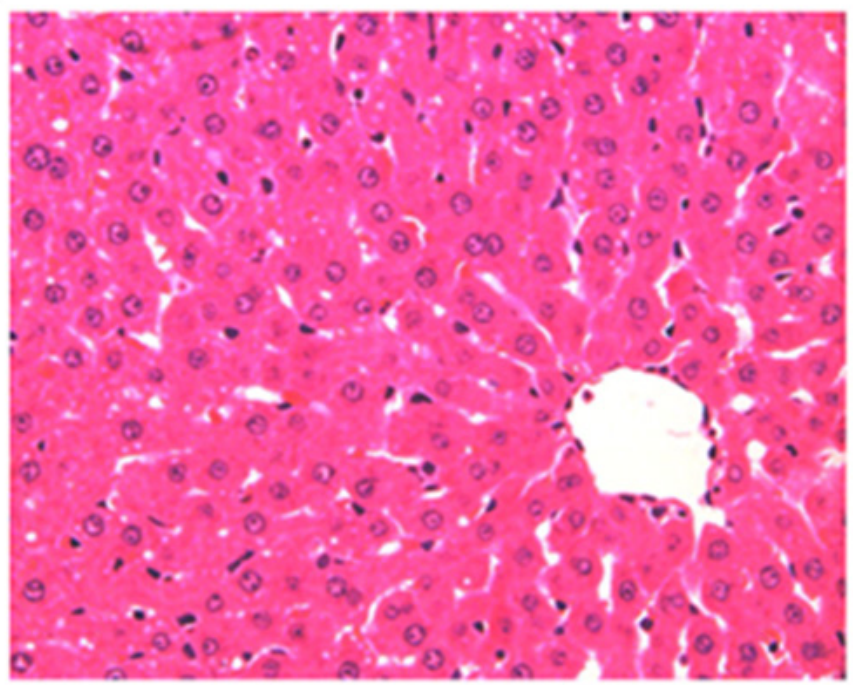

Figure 5 Light micrograph of a section taken from the liver of non diabetic rat treated with vitamin E and stained with H\&E. Section shows normal histological criteria. Central vein (C) is seen in the centre of the hepatic lobule. Hepatocytes (arrow) contain bluish nuclei and granular acidophilic cytoplasm, they are arranged in plates radiating away from the central vein. Sinusoids (arrow head) are located between cellular plates and drain into the central vein. Some macrophages $(M)$ are located inside the sinusoids being fixed to their walls. $X 400$. 


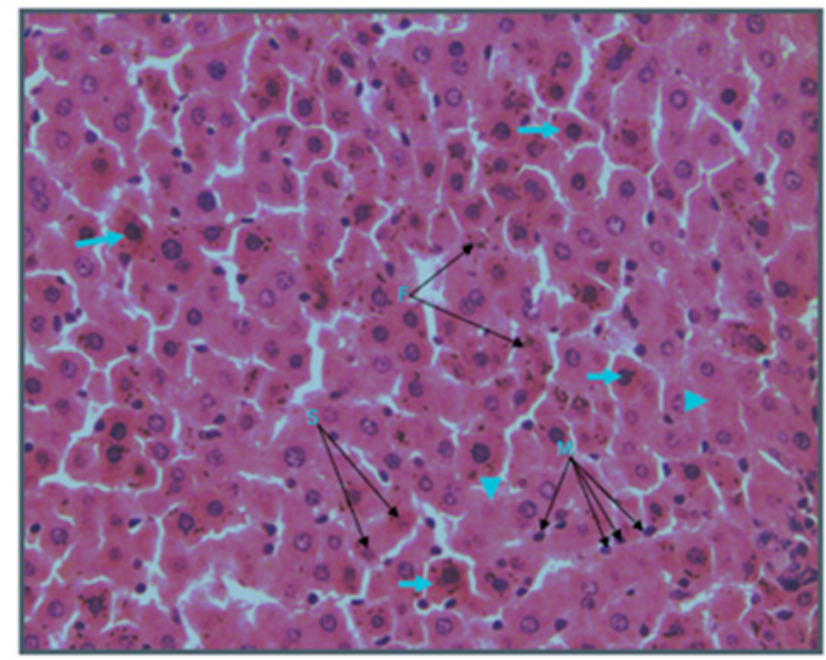

Figure 6 Light micrograph of section of liver taken from non diabetic animal treated with S. polyanthum and stained with H\&E. Cell necrosis is marked throughout the hepatic lobule. Hepatocytes are swollen and contain acidophilic granular or homogenous cytoplasm. Some dead cells have eosinophilic (pink) granular or homogenous cytoplasm and darkly stained nuclei (arrow). Some cells contain small (S) or fragmented (F) nuclei. Some cells have lost their nuclei (arrow head). Liver is infiltrated with large numbers of macrophages (M) $\times 400$.

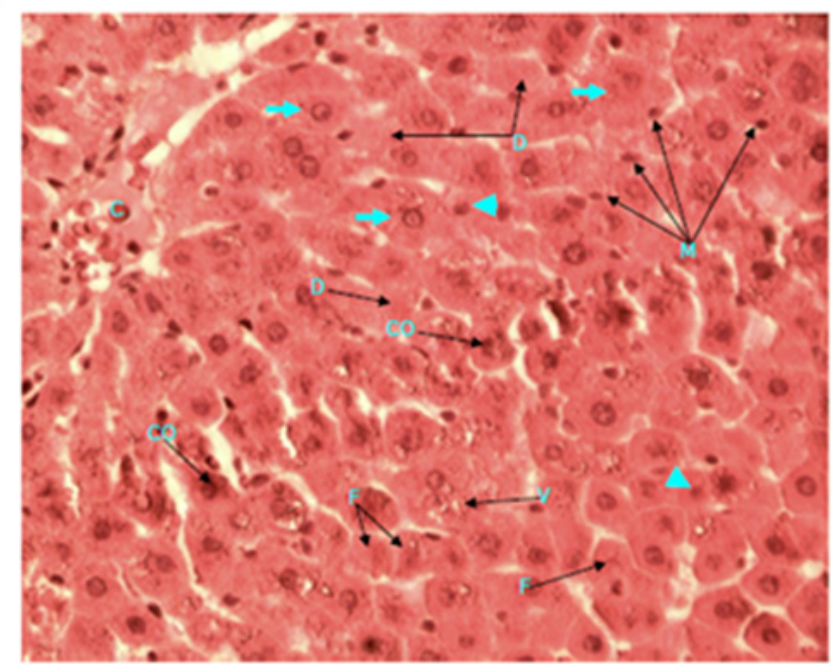

Figure 7 Light micrograph of a section of a diabetic female adult rat liver treated with S. polyanthum extract. Section is stained with H\&E. Central vein (C) in the centre of hepatic lobule is seen. Most of hepatocytes are swollen (arrow). Some of them have small nuclei (arrow head), other cells show nuclear condensation (CO), fragmentation (F) or disappearance (D). Cytoplasm is acidophilic, granular and vacuolated (V) in some cells but is homogeneous in others. Cell membranes are not clearly visible. Macrophage $(\mathrm{M})$ infiltration of the liver is obvious $X 400$.

o. sumatrana treated non diabetic rats: The liver of these rats showed diffused damage of the hepatic cells throughout the hepatic lobules. Hepatocytes sustained marked necrosis. Most cells were swollen and contained destroyed nuclei and eosinophilic (pink) granular or homogenous cytoplasm. Infiltrating macrophages were seen around blood vessels, in sinusoids and between hepatic cells. The damage was graded as of severe type (Figure 9).

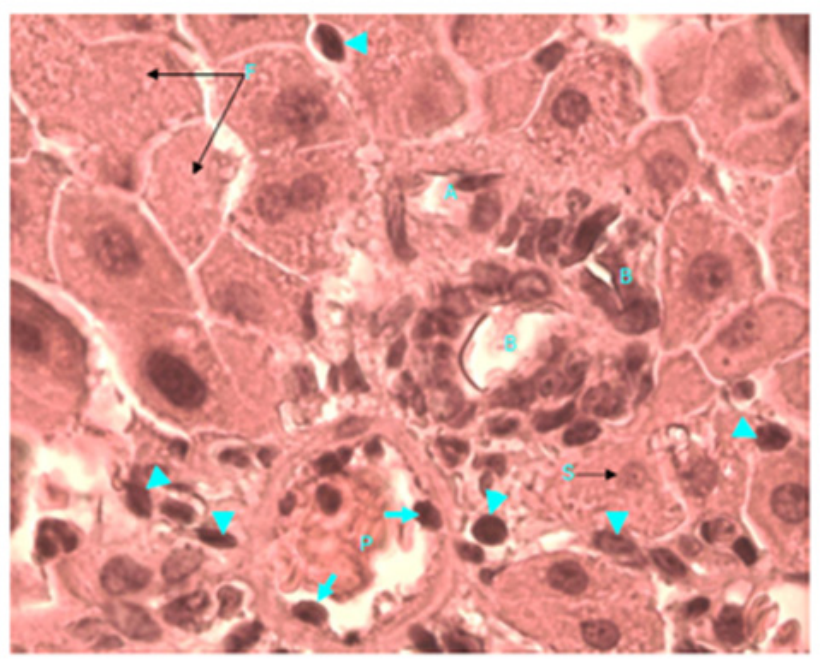

Figure 8 Light micrograph of a section of a diabetic female adult rat liver treated with S. polyanthum extract. H\&E staining. Portal triad shows hepatic portal vein (P) which contains macrophages, some of which (arrow) are penetrating the wall of hepatic portal vein. Other macrophages (arrow head) are seen outside the vessel; they are invading the liver tissue and are spread between hepatocytes. Hepatic artery (A) and bile duct (B) are also seen. Hepatocytes form plates around portal triad. Some of them contain small (S) and others contain fragmented (F) nuclei. Cytoplasm is acidophilic and granular X1000.

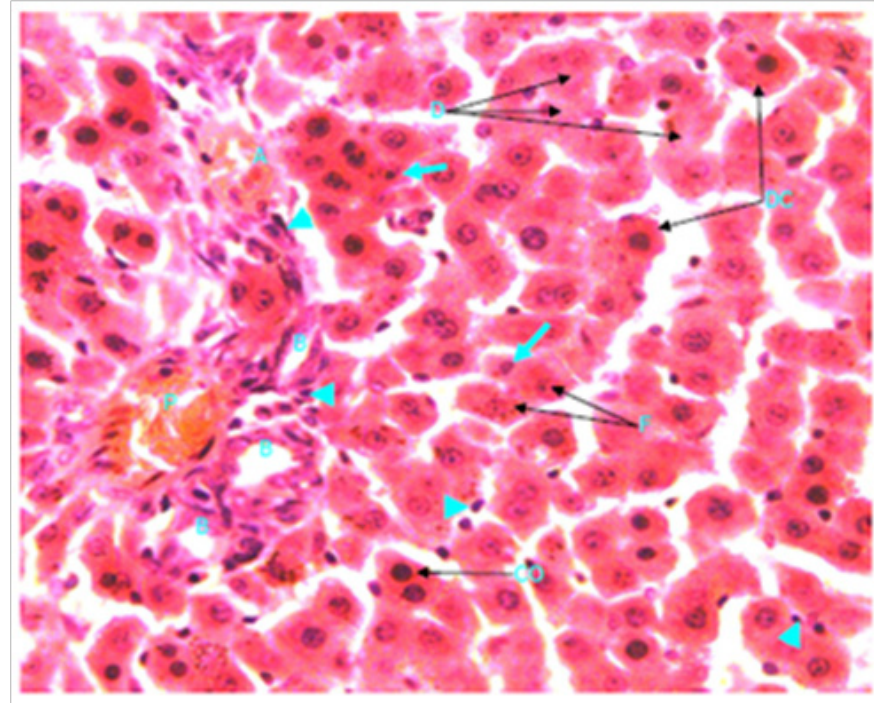

Figure 9 Light micrograph of a section of a non diabetic female adult rat liver treated with $\mathrm{O}$. sumatrana extract. H\&E staining. Note that most hepatocytes are swollen. Some of them contain small nuclei (arrow), other cells show condensation (CO), fragmentation (F) or disappearance of their nuclei (D). Cytoplasm is granular or homogenous. Some dead cells (DC) contain homogenous eosinophilic (pinkish) cytoplasm and dark nuclei. Infiltration with macrophages (arrow head) is noticed around blood vessels in portal triad, inside sinusoids and in between hepatocytes. Portal triad shows a branch of hepatic artery (A), bile duct (B) and hepatic portal vein $(P) \times 400$.

Octomeles sumatrana treated diabetic rats: Animals treated with $O$. sumatrana showed diffuse toxic effect of the extract on their hepatocytes. Cellular necrosis was noticed throughout hepatic lobules. Most hepatocytes were swollen and showed damaged nuclei (small, 
condensed, fragmented or disappeared). Cytoplasm was granular or homogenous, it was acidophilic and sometimes pale. Cell membranes were preserved. Macrophages were seen around portal vein and in between liver cells. The damage is of severe type (Figure 10) (Figure 11).

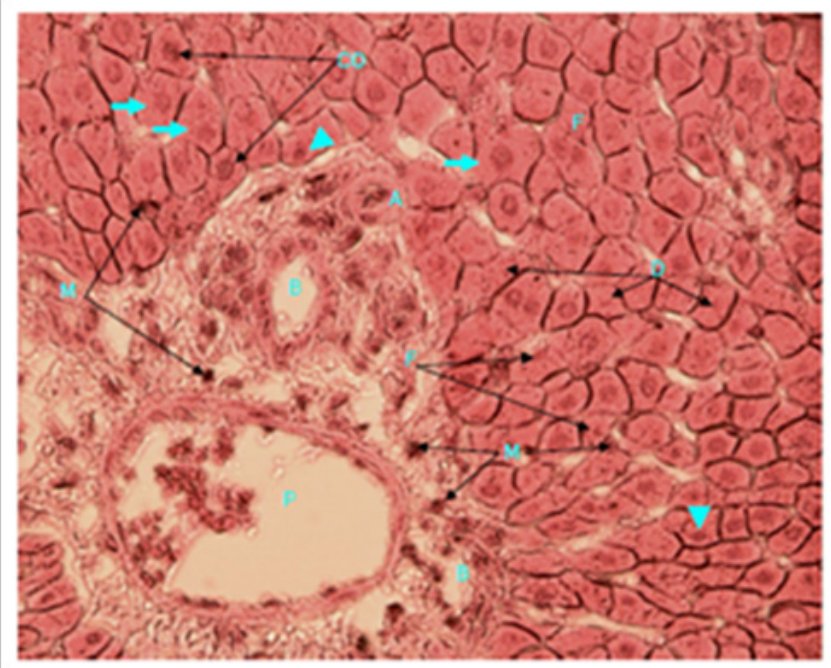

Figure 10 Light micrograph of a section of diabetic female adult rat liver treated with $\mathrm{O}$. sumatrana extract. H\&E staining. Hepatocytes are swollen (arrow). Some have small nuclei (arrow head) others show condensation (CO), fragmentation (F) or disappearance (D) of their nuclei. Cytoplasm is granular but in some other cells, it is homogeneous. Cell membranes are preserved. Macrophages $(M)$ are seen in the area around the portal vein and in between liver cells. Portal triad is visible. Note the hepatic portal vein $(P)$, hepatic artery $(A)$ and bile duct $(B) \times 400$.

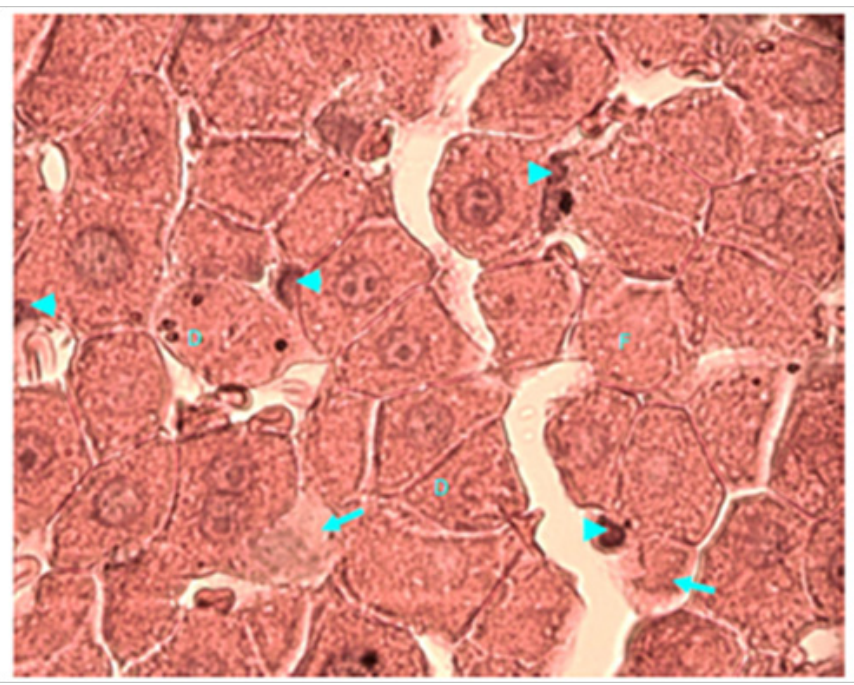

Figure I I Light micrograph of a section of liver taken from non diabetic female adult rat treated with $\mathrm{H}$. polyrhizus. $\mathrm{H} \& \mathrm{E}$ staining. Necrotic hepatocytes are swollen and contain homogenous eosinophilic (pinkish) cytoplasm. Some of their nuclei are small (S), others are dark (D), fragmented (F) or disappeared (D). Marked infiltration of the liver with macrophages (arrow) is noticed; they are seen around the central vein (C), in sinusoids (SI) and between hepatocytes X 400 .

Hylocereus polyrhizus treated non diabetic rats: Animals that were treated with $H$. polyrhizus showed marked necrosis of the liver.
Damage was diffusely affecting hepatic lobules. Damaged hepatocytes were swollen and contained granular or homogenous eosinophilic (pinkish) cytoplasm. Nuclei showed all kinds of damage. Liver was markedly infiltrated with macrophages; they were noticed around central vein, inside sinusoids and between damaged hepatocytes. The damage was of severe type (Figure 12).

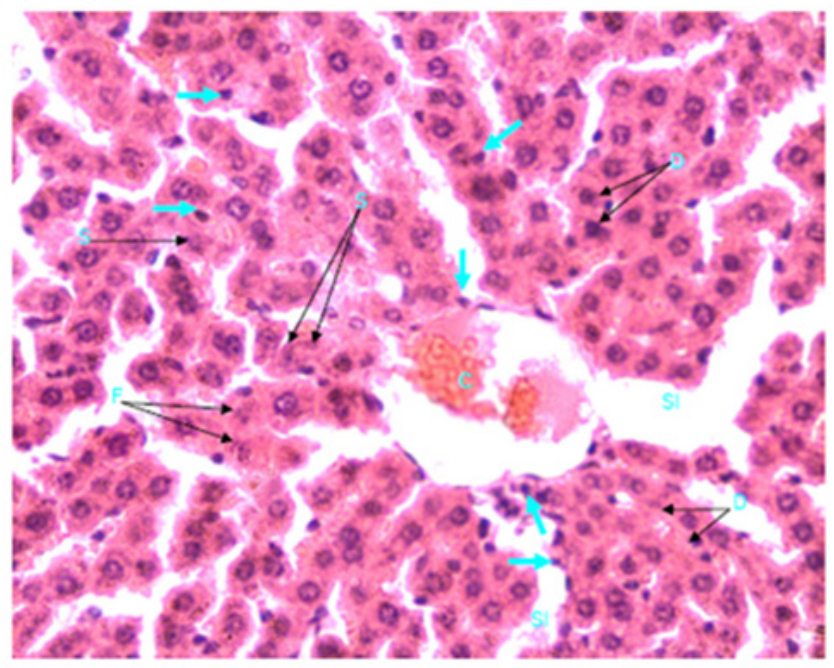

Figure I 2 Light micrograph of a section of liver taken from non diabetic female adult rat treated with $\mathrm{H}$. polyrhizus. $\mathrm{H} \& \mathrm{E}$ staining. Necrotic hepatocytes are swollen and contain homogenous eosinophilic (pinkish) cytoplasm. Some of their nuclei are small (S), others are dark (D), fragmented (F) or disappeared (D). Marked infiltration of the liver with macrophages (arrow) is noticed; they are seen around the central vein (C), in sinusoids (SI) and between hepatocytes $\times 400$.

Hylocereus polyrhizus treated diabetic rats: Animals that were treated with $H$. polyrhizus sustained extensive damage in their livers. Necrosis was profuse and diffusely noticed throughout hepatic lobules. Hepatocytes were swollen with damaged nuclei (small, condensed, fragmented or disappeared). Cytoplasm was granular or homogenous. Cell membranes were damaged. Some cells were converted to a granular, homogeneous mass that stained faintly. There was profuse infiltration of the liver with macrophages. They were profusely noticed around central vein and around vessels in portal triads. They had also spread between damaged hepatocytes. The damage is of severe type (Figures 13-15).

\section{Effect on of plant extracts on kidney}

Normal control rats, control diabetic rats and non diabetic rats treated with vitamin $\mathbf{E}$ : Histology of kidney in these animals was normal. They showed normal renal cortex and medulla. Renal corpuscles and blood vessels were normal. Tubular system in both renal cortex and medulla was normal (Figure 16-18).

Normal non diabetic and diabetic rats treated with S. polyanthum, O. sumatrana and $\boldsymbol{H}$. polyrhizus extracts: All animals that were administered these extracts showed the same severe degree of kidney damage. Kidney changes were:

A. Interstitial bleeding: This was noticed in both cortical and medullary regions of the kidney. Hemorrhagic blood was found around blood vessels and between renal tubules (Figures 19-21) (Figures 23-28). 
B. Extensive thickening (sclerosis) in wall of muscular arteries and arterioles of the kidney:

a. Muscular arteries showed marked thickening of the tunica intema due to proliferation of intemal cells which encroached upon the arterial lumen. Internal elastic lamina and tunica media remained unchanged (Figures 19-21, 23, 26-28).

b. Arteriolar damage was presented as dramatic proliferation of their intemal cells (Figures 21,22,25). These changes might be the cause of disruption of vascular walls and interstitial bleeding.

c. Renal glomerulosclerosis: Renal corpuscles demonstrated diffuse glomerulosclerosis. This was manifested by uniform and homogeneous thickening of the glomerular capillary basement membrane associated with an increase in mesangial cells and matrix. Urinary space remained clear since there had been no proliferation of podocytes (Figure 19, 21-23,25, 26,28).

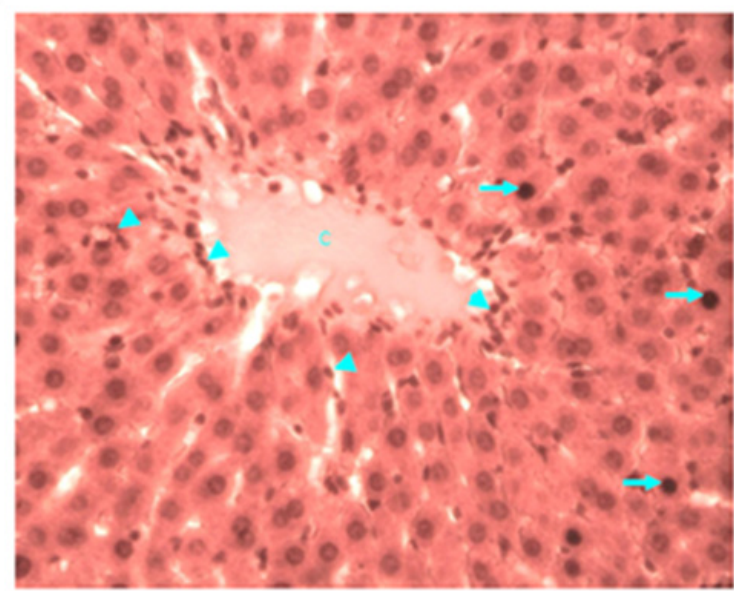

Figure 13 Light micrograph of a section of liver taken from diabetic animal treated with $\mathrm{H}$. polyrhizus. H\&E staining. Note the hepatic lobule with central vein $(C)$ and plates of hepatocytes radiating away from the vein. Some hepatocytes (arrow) are swollen and contain condensed deeply stained damaged nuclei and homogenous cytoplasm. There is profuse infiltration by macrophages (arrow head), they are seen around the central vein, in sinusoids and between hepatocytes $X 400$.

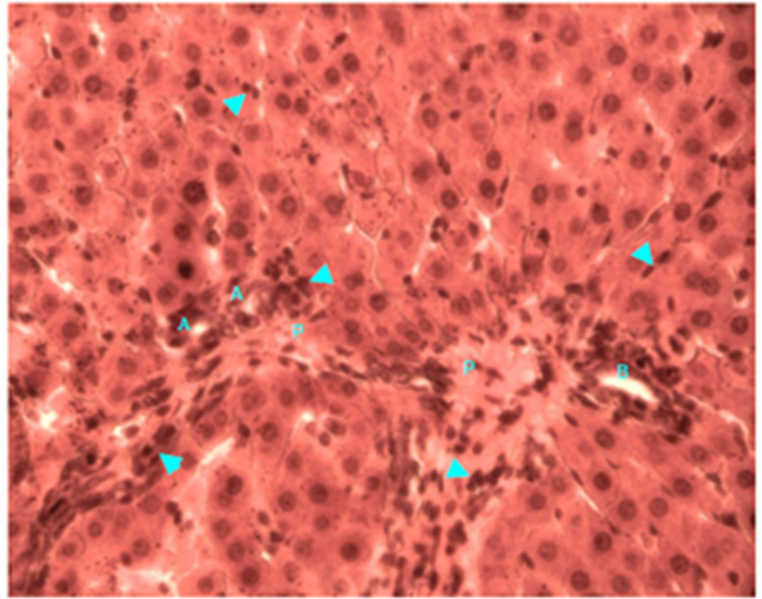

Figure 14 Light micrograph of a section taken from diabetic female adult rat liver. Animal was treated with $\mathrm{H}$. polyrhizus. H\&E staining. Note the portal triad which contains hepatic portal vein $(P)$, hepatic artery $(A)$ and bile duct (B). Macrophages (arrow head) are profusely seen inside the hepatic portal vein, in portal triad outside the vessels and in between hepatocytes $X 400$.

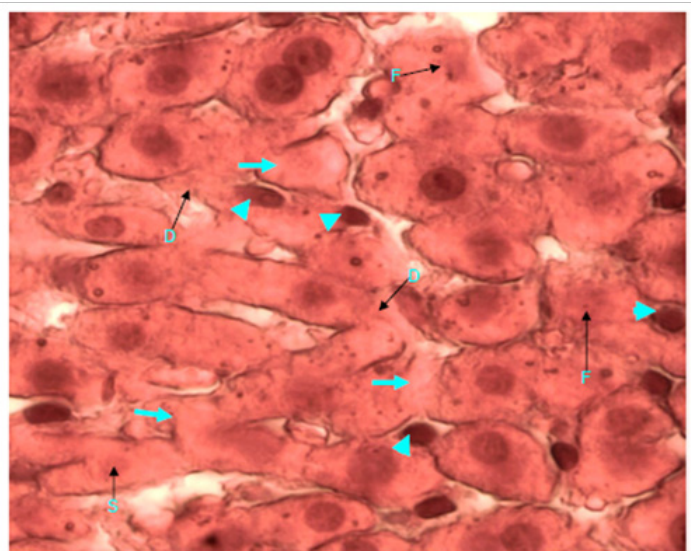

Figure 15 Light micrograph of a section of diabetic female adult rat liver treated with $\mathrm{H}$. polyrhizus. H\&E staining. Necrotic hepatocytes show small $(S)$ and fragmented $(F)$ damaged nuclei. Some cells contain homogenous and faintly stained cytoplasm (arrow). Cell membrane is damaged (D) in other cells. There is marked infiltration of the liver with macrophages (arrow head), they are distributed between the damaged hepatocytes X 1000 .

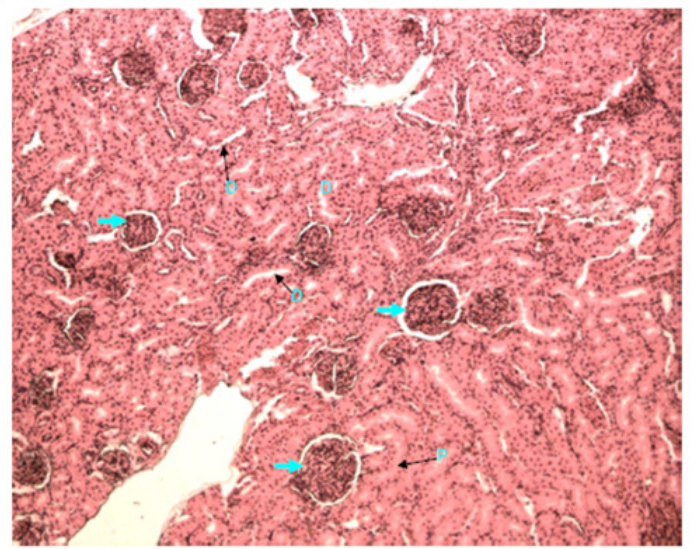

Figure 16 Light micrograph of a section of kidney from normal control female adult rat. H\&E staining. Renal cortex shows normal renal corpuscle (arrow) proximal convoluted tubule $(\mathrm{P})$ and distal convoluted tubule $(\mathrm{D}) \times 100$

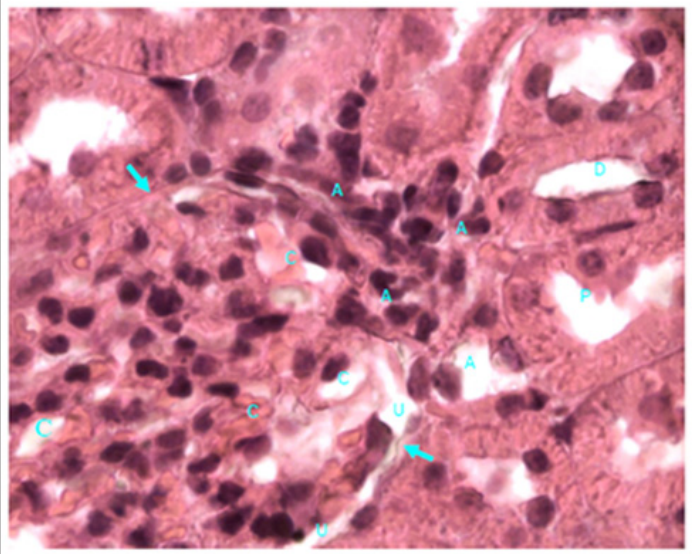

Figure 17 Light micrograph of a kidney section from control diabetic female adult rat. H\&E staining. Renal cortex contains normal renal corpuscle (arrow) Note the normal capillary lumina (C) of the glomerular tuft and the normal urinary space $(U)$. Afferent and efferent glomerular arterioles $(A)$ at hilum of the renal corpuscle have normal wall thickness. Distal convoluted (D) and proximal convoluted $(P)$ tubules are seen $\times 1000$ 


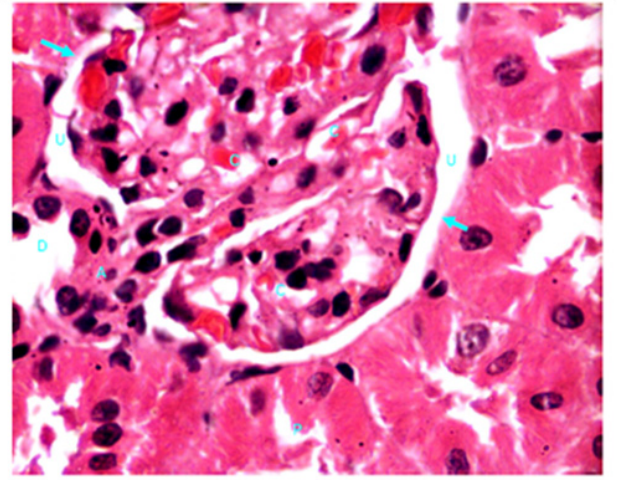

Figure 18 Light micrograph of a kidney section of non diabetic animal treated with vitamin E. H\&E staining. Renal corpuscle (arrow) shows normal glomerular capillary lumina $(C)$ of the glomerular tuft. Urinary space $(U)$ is normal. Glomerular arteriole (A) at hilum of renal corpuscle has normal wall thickness. Proximal (P) and distal (D) convoluted tubules are also noticed XI000.

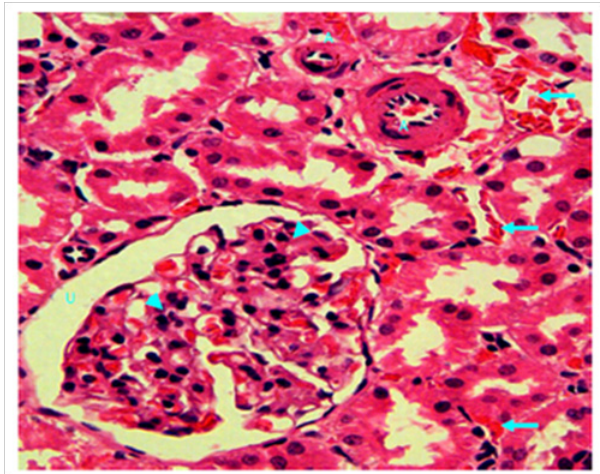

Figure 19 Light micrograph of a kidney section of normal non diabetic rat treated with S. polyanthum. H\&E staining. Marked interstitial bleeding is noticed (arrow). Thickening of wall of muscular artery due to extensive thickening of tunica intema with reduction of lumen diameter is seen (A) Glomerulosclerosis of renal corpuscle manifested by increased cellularity and matrix of the glomerular tuft which have obliterated the capillary lumina is noticed (arrow head). Urinary space $(U)$ remains clear since there has been no proliferation of podocytes. $X 400$.

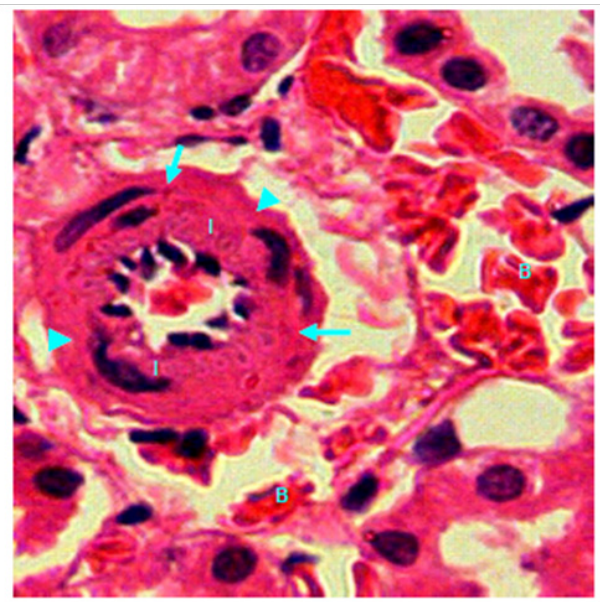

Figure 20 Light micrograph of a kidney section of normal non diabetic rat treated with S. polyanthum. H\&E staining. Renal cortex shows muscular artery, there is marked thickening of the tunica intema (I) due to proliferation of intemal cells which encroached upon the arterial lumen. Internal elastic lamina (arrow) and tunica media (arrow head) remained unchanged. Interstitial bleeding (B) is noticed X400.

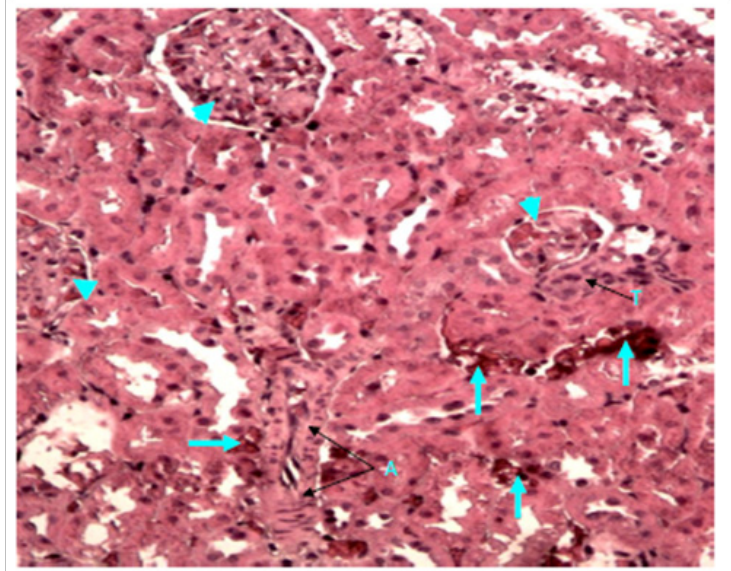

Figure 2I Light micrograph of a kidney section of diabetic rat treated with S. polyanthum extract. H\&E staining. Renal cortex shows hemorrhagic blood between renal tubules (arrow). Thickened wall of muscular artery $(A)$ is noticed. Thickened arteriole (T) is also seen near renal corpuscle. Glomerulosclerosis of renal corpuscles is noticed (arrow head) $\times 200$.

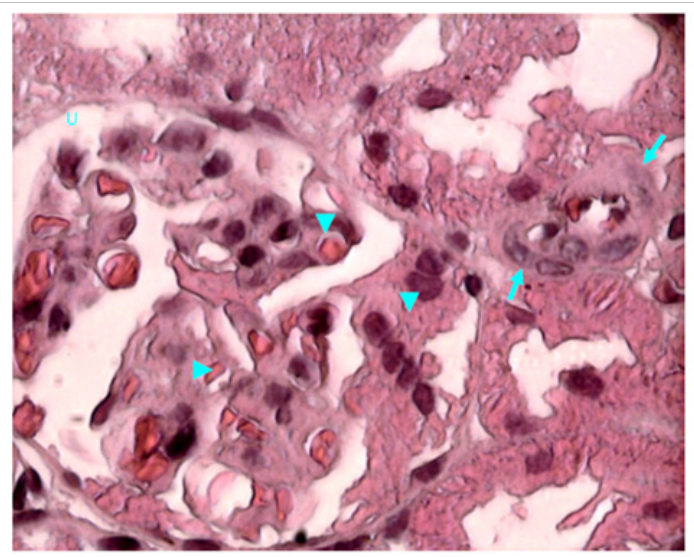

Figure 22 Light micrograph of a kidney section of diabetic rat treated with S. polyanthum extract. H\&E staining. Note that there is an arteriole with thickened wall at the hilum of renal corpuscle (arrow). Glomerulosclerosis of capillary tuft and capillary narrowing is seen inside renal corpuscle (arrow head). Urinary space $(U)$ remains clear X 1000.

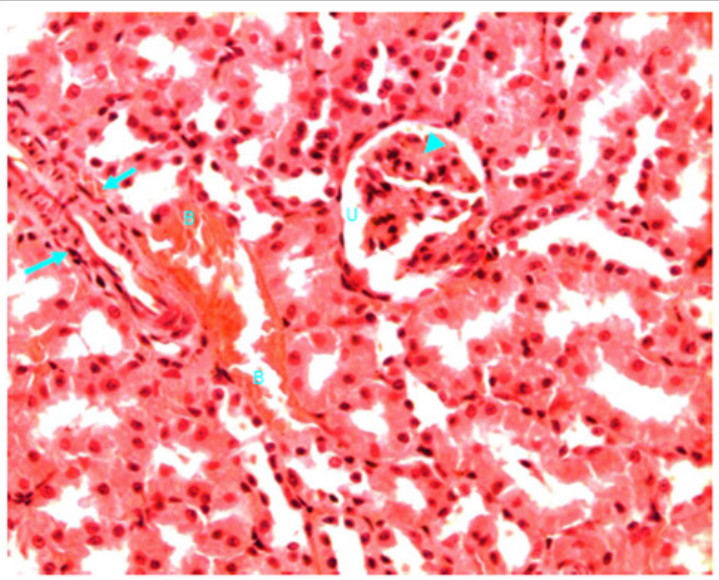

Figure 23 Light micrograph of a kidney section taken from normal non diabetic rat treated with O. sumatrana. H\&E staining. Note the interstitial bleeding (B) between cortical convoluted tubules. Thickened wall muscular artery (arrow) is seen. Glomerulosclerosis of renal corpuscle (arrow head) is noticed. Urinary space $(U)$ is clear $X 400$. 


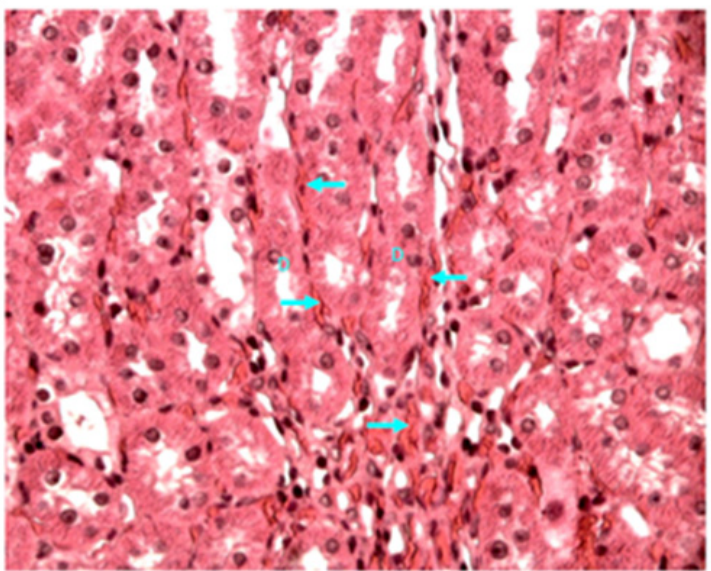

Figure 24 Light micrograph of a section of renal medulla of diabetic animals treated with O. sumatrana extract. H\&E staining. Hemorrhagic blood (arrow) is seen in between the collecting ducts $(\mathrm{D}) \times 400$.

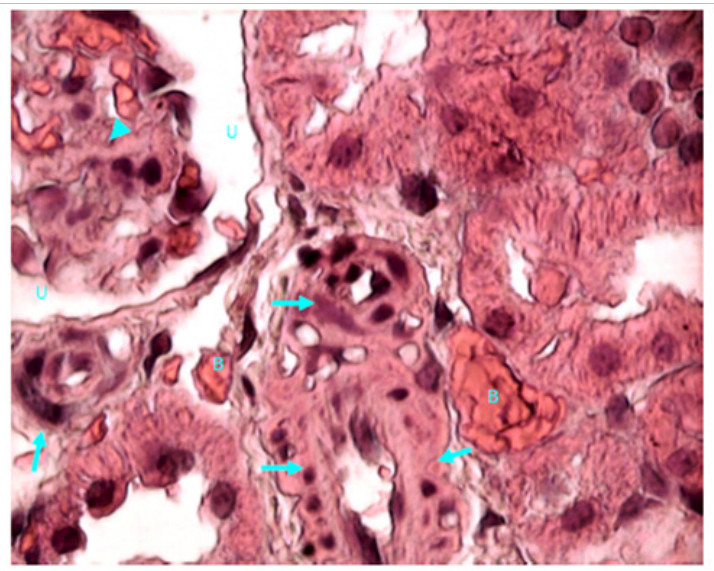

Figure 25 Light micrograph of a section of renal cortex of diabetic rat treated with $\mathrm{O}$. sumatrana extract. H\&E staining. Bleeding (B) is noticed between cortical convoluted tubules. Arterioles at hilum of renal corpuscle shows thickened wall (arrow). Glomerulosclerosis of capillaries of glomerular tuft of renal corpuscle is visible (arrow head). Urinary space of renal corpuscle $(U)$ is normal $X 1000$.

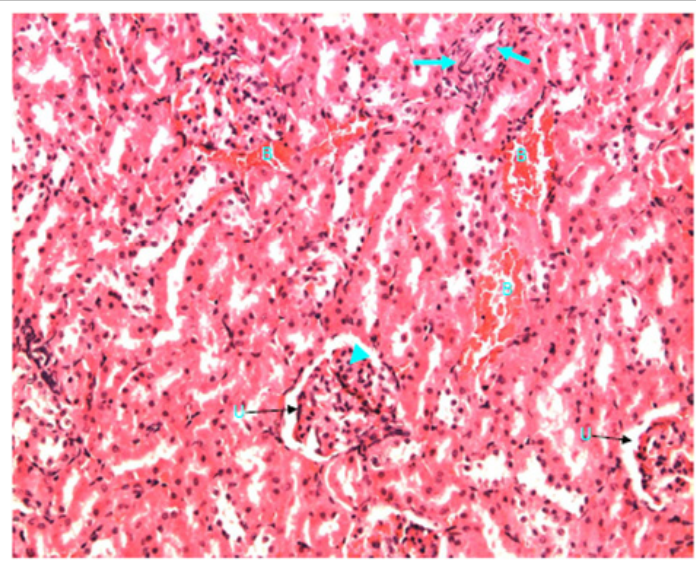

Figure 26 Light micrograph of a kidney section taken from normal non diabetic rat treated with H. polyrhizus. H\&E staining. Interstitial bleeding (B) is seen. Thickened muscular artery (arrow) is noticed. Glomerulosclerosis in renal corpuscle is visible (arrow head), urinary space (U) remains clear X 200.

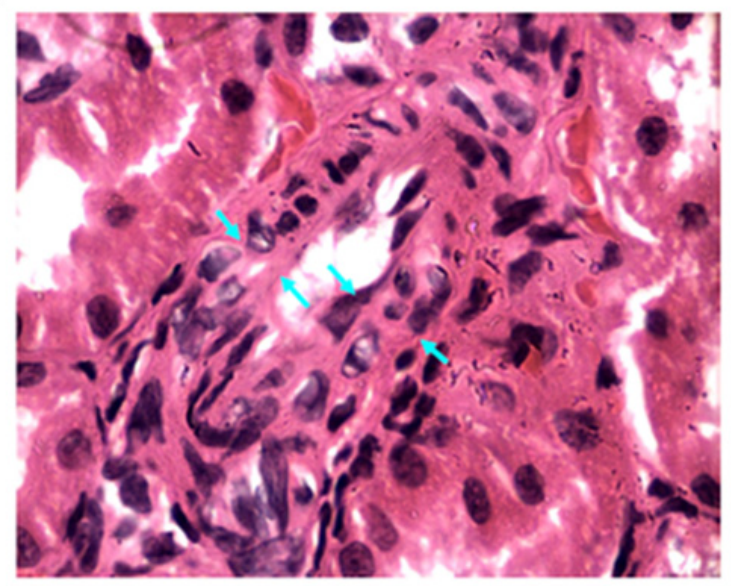

Figure 27 Light micrograph of a kidney section taken from normal non diabetic rat treated with $\mathrm{H}$. polyrhizus. $\mathrm{H} \& \mathrm{E}$ staining. Markedly thickened wall of muscular artery in renal cortex is seen due to extensive thickening of the tunica intema (area limited between opposite arrows). This causes narrowing of the lumen of blood vessel $\times 1000$

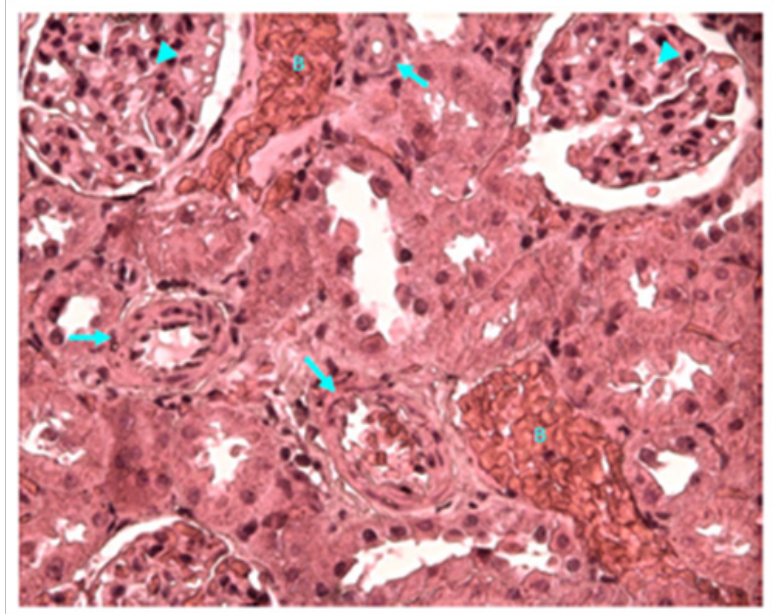

Figure 28 Light micrograph of a section of renal cortex of diabetic female adult rat treated with $\mathrm{H}$. polyrhizus extract. $\mathrm{H} \& \mathrm{E}$ staining. Extensive bleeding (B) in between renal tubules is seen. Muscular arteries with thickened walls (arrow) are noticed. Glomerulosclerosis of glomerular tuft of capillaries of renal corpuscles is visible (arrow head) $\times 400$.

\section{Discussion}

Most fruits and vegetables have antioxidant properties. This is due to their contents of vitamins and polyphenols which can eliminate excessive reactive oxygen species through reducing or scavenging activities or through the chelation of transition metals. Transition metals can promote the production of hydroxyl radicals, a most reactive oxygen species, via the Fenton reaction. Much has been published on the beneficial effects on health of a diet rich in fruits and vegetables.

Oxidative stress is implicated in the onset, development and progression of diabetes mellitus types 1 and 2 ; it also enhances development of diabetic complications such as retinopathy, nephropathy, hypertension and atherosclerotic vascular disease. ${ }^{19-21}$ On other hand, hyperglycemia enhances the formation of free radicals such as superoxide anion radicals, NADPH oxidase-induced reactive 
oxygen species and peroxynitrates. These radicals aggravate glucose auto-oxidation and lipid peroxide formation. ${ }^{22}$ In diabetes mellitus, the antioxidant defenses are affected; this impact is expressed as an impairment of glutathione metabolism, alteration in antioxidant enzymes and decreased ascorbic acid levels. ${ }^{23,24}$ Thus the antioxidant activity of plant extracts through their radical scavenging effect could help in management of diabetes mellitus.

Plants and their extracts are widely used in folk medicine in many countries for management of diseases. Hypoglycaemic effect of natural dietary sources such as garlic, cinnamon extract and black cumin volatile oil had been reported. ${ }^{25-27}$ Amongst the plants with show potential for use in treatment of diabetes mellitus in Malaysia and other Asian countries are S. polyanthum, O. sumatrana and $H$. polyrhizus. These plants were under investigations in faculty of Pharmacy, UiTM laboratories for the last few years.

The high doses of the extracts used in this study were determined on the basis of previous biochemical studies. They were the highest relatively safe and effective doses in terms of antioxidative and antihyperglycaemic activities. This study showed that the plant extract had severely damaged the liver cells (hepatocytes) in diabetic and in normal non diabetic rats. Hepatic damage was associated with infiltration by macrophages. This finding is similar to that shown on the damaging effect of other exogenous toxins on the liver. $1^{4,15}$ Macrophage infiltration of the liver is expected since it is a normal event that happens following necrosis of hepatocytes.

Plant extracts had also damaged the kidney in diabetic and normal non diabetic rats. Their impact was demonstrated as interstitial bleeding, extensive thickening of the wall of muscular arteries and arterioles and glomerulosclerosis of renal corpuscles. Interstitial bleeding was due to damaged arteriole walls. Thickened wall of muscular arteries and arterioles was the result of extensive thickening of the tunica intema which was produced by proliferation of intemal cells. These arterial thickening encroached upon their lumen and narrowed them, thus ischemia of the kidney and their renal corpuscles would be expected. Similar vascular changes were reported in hypertension and in diabetic nephropathy. ${ }^{14,15}$ Dose-dependent thickening of the endometrial blood vessels was also noticed in rats treated with crude methanolic leaf extract of Aspilia Africana (150 to $300 \mathrm{mg} / \mathrm{kg}$ body weight, p.o. daily for 30 days). ${ }^{28}$ Dose-dependent damaging of the kidney was also noticed in rats after treatment with aqueous leaf extract of rinbacin, the renal pathologic changes was manifested by damaged glomeruli and tubules. ${ }^{16}$

Glomerulosclerosis of glomerular tuft of capillaries in renal corpuscles was an extension to the changes that happened in arteries and arterioles. Narrowing of glomerular capillaries was due to a uniform and homogeneous thickening of the glomerular capillary basement membrane which was associated with an increase in mesangeal cells and matrix. Urinary space remained clear since there had been no proliferation of podocytes. Such changes were also reported in chronically ischaemic glomeruli and in diabetic nephropathy. ${ }^{14,15}$

Three types of controls were compared with animals given the plant extracts, they were normal, normal diabetic and normal non diabetic rats treated with vitamin $\mathrm{E}$, a well known antioxidant. Our data (unpublished) showed the three plant extract to have high antioxidant capacity, thus the use of vitamin $\mathrm{E}$ as the control antioxidant. Vitamin E enhanced wound healing in normal and diabetic rats. ${ }^{29}$ Its administration in this study did not implicate any effects on rat liver and kidney. The other two controls also showed normal liver and kidney.

Little is known of the phytochemical constituents of $O$. sumatrana. Early studies on S. polyanthum showed it to contain flavonoids, tannins and alkaloids [30]. Other species of the same family, S. commersonii, $S$. glomeratum and $S$. mauritianum were shown to contain high levels of phenolic compounds. ${ }^{31} \mathrm{H}$. polyrhizus has high content of betacyanins, red-violet pigments from the betalain family. ${ }^{11,32,33}$ Tannins are polyphenols. All plants contain tannins which contribute to the astringent taste of vegetables. The content of tannins in S. polyanthum is expected to be high based on its high content of polyphenols. Food rich in tannins exert a growth depressing effect in rats and chicken. ${ }^{34}$ At the high daily doses used in this study $(1 \mathrm{~g} / \mathrm{kg}$ for $S$. polyanthumand $O$. sumatrana, $3 \mathrm{~g} / \mathrm{kg}$ for $H$. polyrhizus), treatment of rats for two weeks has resulted in marked pathological changes in their liver and kidney, although the animals exhibited no obvious morbidity or significant loss in body weight. The offending chemical(s) is unknown but the toxicity of tannins and/other polyphenols could not be ruled out. More studies are required to monitor the safe use of the studied plants and their extracts in traditional medicine.

\section{Conclusion}

This work demonstrated the importance of safety studies on herbal extracts. Natural products are not necessarily safe especially at the higher dose range or when an extract is taken for prolonged periods of time.

\section{Acknowledgements}

Prof. Dr. AA. H. Dhiab Al-Nuaimi is most grateful to Prof. Dr. Aishah Adam, Faculty of Pharmacy, Universiti Teknologi MARA, for her unlimited support and encouragement. He is also indebted to $\mathrm{Al}$ Balqa Applied University, Al Salt, Jordan, for their support.

\section{Conflict of interest}

The study was supported by a research grant from the Ministry of Science, Technology and Innovation (MOSTI), to whom the author is most grateful.

\section{References}

1. Aggarwal BB, Harikumar KB. Potential therapeutic effects of curcumin, the anti-inflammatory agent, against neurodegenerative, cardiovascular, pulmonary, metabolic, autoimmune and neoplastic diseases. Int J Biochem Cell Biol. 2009;41(1):40-59.

2. Efferth T, Kain B. Toxicities by herbal medicines with emphasis to traditional chinese medicine. Curr Drug Metab. 2011;12(10):989-996.

3. Vecchia CL, Altieri A, Tavani A. Vegetables, fruit, antioxidants and cancer: a review of Italian studies. Eur J Nutr. 2001;40(6):261-267.

4. Mc Guire M, Beerman KA. Nutritional sciences from fundamentals to food. 3rd ed. Cengage, USA; 2017.

5. Santos Buelga C, Scalbert A. Proanthocyanidins and tannin-like compounds - nature, occurrence, dietary intake and effects on nutrition and health. J Sci Food Agric. 2000;80(7):1094-1117.

6. Sun J, Shi J, Jiang Y, et al. Identification of two polyphenolic compounds with antioxidant activities in longan pericarp tissues. J Agric Food Chem. 2007;55(14):5864-5868. 
7. Norman J. Spices. London: Dorling Kindersley Ltd; 1990.

8. Marks C. The exotic kitchen of Indonesia. New York: M. Evans and Company; 1993.

9. Sayekti S, Muhtadi A, Supriyatna. Aktivitas hipoglikemik daun salam dan herba bulu lutung. CerminDuniaKedokteran. 1994;95:50-54.

10. Mizrahi Y, Nerd A. Climbing and columnar cacti: New arid land fruit crops In: Janick J, editor. Perspectives on new crops and new uses. Alexandria: ASHS Press; 1999. p. 358-366.

11. Stintzing FC, Schieber A, Carle R. Betacyanins in fruits from red-purple pitaya, Hylocereus polyrhizus (Weber) britton and rose. Food Chem. 2002;77(1):101-106.

12. Chandalia M, Garg A, Lutjohann D, et al. Beneficial effects of high dietary fiber intake in patients with type 2 diabetes mellitus. $N$ Engl $\mathrm{J} \mathrm{Med}$. 2000;342(19):1392-1398.

13. Arbo MD, Larentis ER, Linck VM, et al. Concentrations of p-synephrine in fruits and leaves of Citrus species (Rutaceae) and the acute toxicity testing of Citrus aurantium extract and p-synephrine. Food ChemToxicol. 2008;46(8):2770-2775.

14. Wheater P, Burkitt G, Stevens A, et al. Basic histopathology, a text and colour atlas. Edinburgh: Churchill Livingstone; 1985.

15. Woolf N (1998) Pathology, basic and systemic. London: WB Saunders Company Ltd; 1998.

16. Afonne OJ, Orisakwe OE, Dioka CE, et al. Effects of rinbacin extract on rat kidney. Biol Pharm Bull. 2002;25(8):1022-1025.

17. Fakher SH, Djalali M, Tabei SM. Effect of Vitamins A, E, C and Omega-3 Fatty Acids on Lipid Peroxidation in Streptozotocin Induced Diabetic Rats. Iranian J Publ Health. 2007;36(2):58-63.

18. Abdo EE, Cunha JE, Deluca $P$, et al. Protective effect of N2 mercaptopropionylglycine on rats and dogs liver during ischemia/ reperfusion process. Arq Gastroenterol. 2003;40(3):177-180.

19. Purushothaman KR, Meerarani P, Morene PR. Inflammation and neovascularization in diabetic atherosclerosis. Indian $J$ Exp Biol. 2007;45(1):93-102.

20. Valko M, Leibfritz D, Moncol J, et al. Free radicals and antioxidants in normal physiological functions and human disease. Int $J$ Biochem Cell Biol. 2007;39(1):44-84.
21. Kastelan S, Tomic M, Mrazovac V. Pharmacotherapy for diabetic retinopathy-it is not just a dream. Diabetologia Croatica. 2008;37(3):57-66.

22. Maritim AC, Sanders RA, Watkins III JB. Diabetes, oxidative stress, antioxidants: a review. J Biochem Mol Toxic. 2003;17(1):24-38.

23. Ravi K, Ramachandran B, Subramanian S. Effect of Eugenia Jambolana seed kernel on antioxidant defense system in streptozotocin-induced diabetes in rats. Life Sci. 2004;75(22):2717-2731.

24. Kumar GP, Arulselvan P, Kumar DS, et al. Anti-diabetic activity of fruits of Terminalia chebula on streptozotocin induced diabetic rats. Journal of health science. 2006;52(3):283-291.

25. Babu PS, Prabuseenivasan S, Ignacimuthu S. Cinnamaldehyde-A potential antidiabetic agent. Phytomedicine. 2007;14(1):15-22.

26. Haque ME, Safayetullah Q, Ahsan M, et al. Hypoglycaemic property of nutraceuticals. J Pharm Sci. 2007;6(2):105-107.

27. Mc Culloch M. Herbs and spices: cinnamon's link to diabetes control. Today's dietitian. 2015;17(11):12.

28. Oluyemi KA, Okwuonu UC, Baxter DG, et al. Toxic effects of methanolic extract of Aspilia africana leaf on estrous cycle and uterine tissues of Wistar rats. Int J Morphol. 2007;25(3):609-614.

29. Musalmah MM, Fairuz AH, Gapor MT, et al. Effect of vitamin E on plasma malondialdehyde, antioxidant enzyme levels and the rates of wound closures during wound healing in normal and diabetic rats. Asia Pacific J Clin Nutr. 2002;11(7):448-451.

30. Ivorra MD, Paya M, Villar A. A review of natural products and plants as potential antidiabetic drugs. J Ethnopharmacol. 1989;27(3):243-275.

31. Vidushi S, Neergheen MA, Soobrattea TB, et al. Characterisation of the phenolic constituents in Mauritian endemic plants as determinants of their antioxidant activities in vitro. J Plant Physiol. 2006;163(8):787-799.

32. Wybraniec S, Platzner I, Geresh S, et al. Betacyanins from vine cactus Hylocereus polyrhizus. Phytochemistry. 2001;58(8):1209-1212.

33. Wybraniec S, Nowak Wydra B, Mitka K, et al. Minor betalains in fruits of Hylocereus species. Phytochemistry. 2007;68(2):251-259.

34. Reed JD. Nutritional toxicology of tannins and related polyphenols in forage legumes. J Anim Sci. 1995;73(5):1516-1528. 